\title{
Detecting pre-eruptive magmatic processes of the 2018 eruption at Kilauea, Hawaii volcano with ambient noise interferometry
}

Kuan-Fu Feng ${ }^{1,2}$, Hsin-Hua Huang ${ }^{2^{*}}$ (i) and Yih-Min Wu ${ }^{1,2}$

\begin{abstract}
A sequence of eruptions in the lower East Rift Zone (LERZ) of the Kilauea, Hawaii volcano commenced in early May 2018 and caused serious damage and residential evacuation. The post-eruption drainage and collapses of the summit lava lake and caldera suggest a well-connected magmatic plumbing system along the rift zone. How and when the pre-eruptive magmatic processes in such connecting system occurred are, however, still unclear. For that, we apply ambient noise interferometry with seismic data from January 2017 to June 2018 from 12 broadband seismometers to investigate spatiotemporal seismic velocity changes $(\mathrm{d} v / v)$ of the upper crust in the Kilauea area. The $\mathrm{d} v / \mathrm{v}$ variations in three frequency bands $(0.3-0.6 \mathrm{~Hz}, 0.6-0.9 \mathrm{~Hz}$, and $0.9-2.0 \mathrm{~Hz})$ show distinct responses to strong earthquake ground shaking and deep magmatic intrusion processes. Earthquake-induced $d v / v$ drops mainly in the higher two frequency bands imply shallow mechanical changes within the uppermost $1 \mathrm{~km}$ of the crust. In contrast, the magmarelated dv/v changes can be characterized into three periods of activity: from the December 2017 to March 15, 2018, a $d v / v$ excursion only seen in the lowest frequency band indicates the magmatic intrusion processes taking place at the depth range of 1-4 km, consistent with the proposed depth of the magma reservoir-dike system in the rift zone. The spatial $d v / v$ distribution suggests that the magma may intrude to the deeper summit magma reservoir and in the upper East Rift Zone (UERZ) at this time. From March 15 to April 17 in 2018, the summit inflation recorded by tiltmeters causes the $\mathrm{dv} / \mathrm{v}$ increases in the higher two frequency bands. After April 17 to the eruption, the accumulating damage of the edifice together with the stronger intrusion activity in the UERZ result in $\mathrm{d} v / v$ decreases in all three frequency bands around the summit and UERZ areas. Our observations highlight that the ambient noise interferometry analysis provides an opportunity to image and understand the pre-eruptive processes of reservoir-dike magma system and could be a useful supplement to current volcanic monitoring systems.
\end{abstract}

Keywords: Ambient noise interferometry, Seismic velocity change, Pre-eruptive magmatic processes, Kilauea volcano, Frequency-dependent analysis

\section{Introduction}

The lower East Rift Zone eruption of the Kilauea volcano The 2018 eruption of the Kilauea volcano began in early May and created a series of new fissures in the lower East Rift Zone (LERZ, Fig. 1). The Hawaiian Volcano Observatory (HVO) issued notices of magma pressurization at $\mathrm{Pu}^{\prime} \mathrm{u}^{\prime} \overline{\mathrm{O}}^{\prime} \mathrm{o}$ on April 17 and lava overflowed from

\footnotetext{
*Correspondence: hhhuang@earth.sinica.edu.tw

${ }^{2}$ Institute of Earth Sciences, Academia Sinica, Taipei 11529, Taiwan Full list of author information is available at the end of the article
}

the Halema'uma'u crater on April 26. Before the end of April, Pu' ${ }^{\prime} \bar{O}^{\prime}{ }^{\prime}$ crater collapsed and a burst of seismicity occurred, migrating eastward from the middle East Rift Zone (MERZ) to the LERZ. On May 2, the first fissure opened near Leilani Estates followed by a series of new fissures opening in the LERZ. Until September 2018, lava flows have covered $35.5 \mathrm{~km}^{2}$ of land and destroyed over 700 homes (Neal et al. 2019; Patrick et al. 2019). This protracted eruption drained magma from the summit reservoir and induced a series of caldera collapses $\sim 40 \mathrm{~km}$ away, suggesting a well-connected magmatic plumbing 


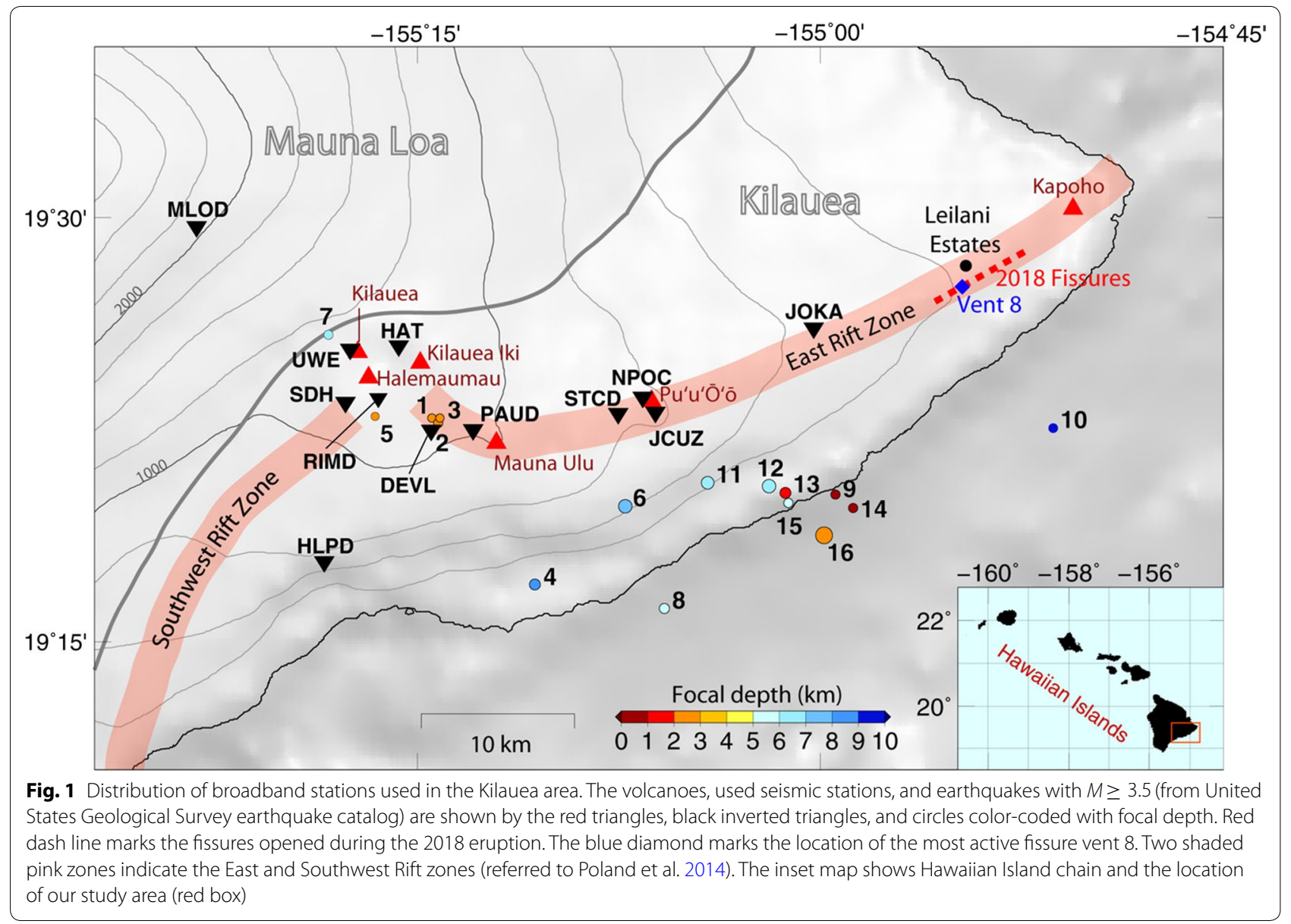

system along the East Rift Zone (Neal et al. 2019; Wu et al. 2020). However, when and how such connecting plumbing system formed, stored and transported magma from the summit to its lower flank prior to the eruption remains poorly understood.

\section{Ambient noise interferometry (ANI) for monitoring volcanoes}

The ambient noise interferometry (ANI) has become a promising tool for monitoring volcanic unrest and magma pressurization at depths in the past decade (Brenguier et al. 2008, 2014). The pioneer study (Brenguier et al. 2008) at volcano Piton de la Fournaise (PdF) found consistent decreases in seismic velocity a few weeks before eruptions over several cycles from 1999 to 2000 and suggested that precursory velocity decreases are caused by the inflation of volcanic edifice. These inflation-related velocity decreases prior to eruptions have been observed in later studies at PdF (Duputel et al. 2009; Obermann et al. 2013a) and other volcanoes (Mordret et al. 2010; Bennington et al. 2015, 2018; MachaccaPuma et al. 2019); However, velocity increases related to pre-eruptive inflation have also been found at volcanoes as Miyakejima volcano (Anggono et al. 2012), Merapi volcano (Budi-Santoso and Lesage 2016), and Kilauea volcano (Donaldson et al. 2017). Such contradiction can be reconciled with a model based on strain theory proposed by Donaldson et al. (2017). They showed whether the edifice undergoing extension or compression depends on the depth of inflating magma reservoir. The modeling of shallow magma reservoir at Kilauea (1-2 km below the surface) suggests that the most of the edifice is dominated by compression and hence results in increases of seismic velocity. Investigations on the variations in seismic velocity before eruptions can thus provide valuable insights into the strain state of the magmatic systems in response to the intrusion processes (Brenguier et al. 2008; Bennington et al. 2018).

For the May 2018 eruption of the Kilauea volcano, a recent study of Olivier et al. (2019) has observed seismic velocity increases and subsequent decreases in response to the inflation recorded by tiltmeters beginning from March and the accumulating damage of the volcano edifice 10 days before the eruption. These observations are, 
however, more focusing on short-term precursory activity around the summit. To further understand the magma connectivity and interactions between the summit and LERZ, we conduct ANI analysis in broader space and time to monitor and detect possible mechanical or structural changes in seismic velocity $(\mathrm{d} v / v)$ associated with pre-eruptive magmatic intrusion processes. Using the vertical component of daily seismic recordings from 12 selected broadband seismic stations distributed around the summit and along the ERZ from January 2017 to June 2018 (Fig. 1), we measure $\mathrm{d} v / v$ in three distinct frequency bands of $0.3-0.6 \mathrm{~Hz}, 0.6-0.9 \mathrm{~Hz}$, and $0.9-2.0 \mathrm{~Hz}$. The frequency-dependent responses of $\mathrm{d} v / v$ clearly show different mechanisms related to earthquake ground shaking and magmatic intrusion processes in different depth ranges. Spatiotemporal $\mathrm{d} v / v$ patterns that mainly show velocity decreases along the upper East Rift Zone (UERZ) and increases around the summit and surrounding areas suggest that magmatic intrusion processes beginning from December 2017 until the May 2018 eruption reflect dike-reservoir inflation and edifice accumulating damage in three stages.

\section{Background of Kilauea volcano}

The Kilauea volcanic area consists of a main summit and two rift zones, the East Rift Zone (ERZ) and the Southwest Rift Zone (SWRZ). In the past 30 years, major eruptions at Kilauea have occurred along the ERZ between the summit and $\mathrm{Pu}^{\prime} \mathbf{u}^{\prime} \mathrm{O}^{\prime} \bar{o}$ (Fig. 1) and built up a series of cones along the linear fissures of the rift. The last eruption happened in 2008 followed by several months of increased sulfur dioxide emissions and seismicity and formed a lava lake within Halema 'uma'u crater at Kilauea's summit. The active and connected magmatic plumbing system beneath the Kilauea volcano includes a shallow magma reservoir at $\sim 1 \mathrm{~km}$ beneath the Halema 'uma'u crater (Halema'uma 'u reservoir), a deeper magma reservoir at a depth of $\sim 3 \mathrm{~km}$ below the southern side of the Kilauea caldera (Southern Caldera reservoir), and two dike systems extending from the summit to the SWRZ and ERZ (Heliker et al. 2003; Poland et al. 2014; Pietruszka et al. 2015; Chen et al. 2019).

Two types of volcanic tremors have long been recognized beneath the region of Kilauea summit: (1) the first is related to the degassing and spattering of the lave lake surface (Patrick et al. 2016a, b), which can been seen in between 0.3 and $0.8 \mathrm{~Hz}$ in the amplitude spectrogram of station UWE (Fig. 2a); and (2) the second is related to the fluid-rock interactions in the conduits, which can be found in the band $0.01-0.1 \mathrm{~Hz}$ as very long-period tremor signals (Patrick et al. 2011; Dawson and Chouet 2014).
Geodetically, the spreading of the ERZ is primarily unilateral according to global positioning system (GPS) observations (Owen et al. 2000). In contrast to the relatively inactive northern flank, the southern flank displaces seaward on a north-dipping basal decollement at a depth of approximately 7-9 km owing to the effects of magma injection into the rift zones and the topographic load of the island (Dieterich 1988; Denlinger and Okubo 1995; Dieterich and Cayol 2003; Heliker et al. 2003; Poland et al. 2017).

\section{Methods}

\section{Ambient noise interferometry (ANI) to measure $\mathrm{d} v / \mathrm{v}$}

ANI is used to probe the time-lapse changes of subsurface medium in the Kilauea volcanic area. By cross-correlating and stacking sufficiently long time series of seismic data, the noise correlation functions (NCFs) between two stations will in principle approximate to Green's functions as propagating from one station to the other (Lobkis and Weaver 2001; Snieder et al. 2002), including both direct ballistic waves and multiple-scattering coda waves (Sens-Schönfelder and Wegler 2006). Because of multiple-scattering, coda waves have much longer paths than direct waves and are more sensitive to changes in medium and less sensitive to changes in the noise source (Colombi et al. 2014). Based on the assumption of homogeneous velocity changes in the medium, the time shifts $(\mathrm{d} t / t)$, if present, between coda waves of two NCFs on different days can be used to characterize the average seismic velocity change $(\mathrm{d} v / v)$ of the medium via the equation (Snieder et al. 2002):

$$
\mathrm{d} t / t=-\mathrm{d} v / v .
$$

We analyze 1.5 years of continuous vertical-component seismic records (January 2017 to June 2018) from 12 broadband seismic stations (Fig. 1) distributed around the summit and along the ERZ. We also include two additional stations (MLOD and HPLD) which are located in northwest and southwest about $10 \mathrm{~km}$ away from the summit for a better station coverage. In data preprocessing, we cut the continuous data into 1-day-long segments and remove the instrumental response for each trace. The daily waveforms are demeaned, detrended, tapered, and decimated from 100 to $25 \mathrm{~Hz}$. Amplitude spectrograms are calculated to show the frequency content of the data recorded by stations from the summit toward the MERZ over time (Fig. 2 and Additional file 1: Figure S1). A clear seasonality that shows lower amplitude in the summer (June-August) is observed in frequencies between $\sim 0.1$ and $0.3 \mathrm{~Hz}$ from the oceanic secondary microseism as previously reported (Donaldson et al. 2017). For the higher frequency range, the volcanic tremor signals from the Halema'uma' $u$ and $\mathrm{Pu}^{\prime} u^{\prime} \bar{O}^{\prime}{ }^{\prime} \mathrm{c}$ craters are most 


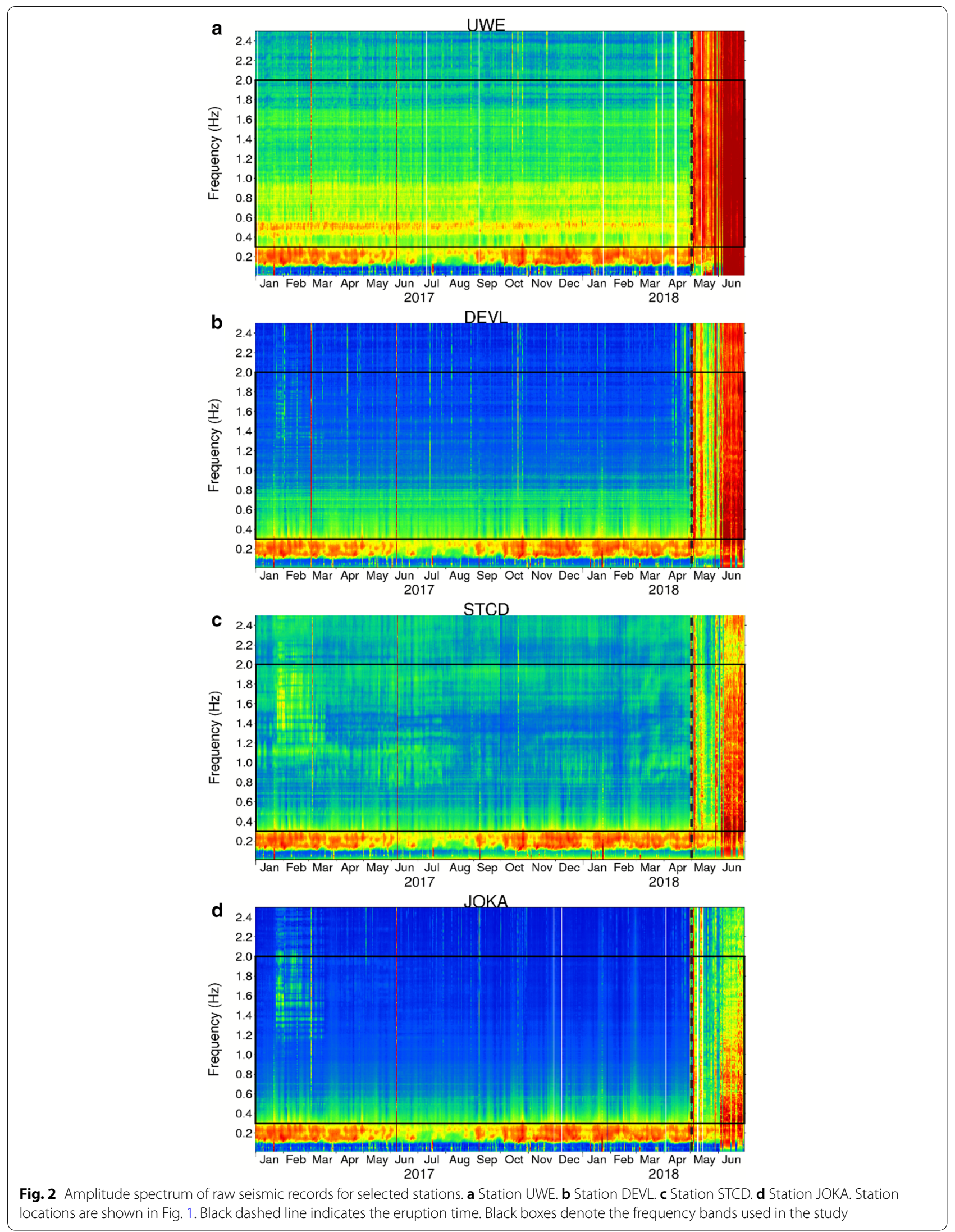


visible in $0.4-0.6 \mathrm{~Hz}$ at Station UEW and in $0.8-1.5 \mathrm{~Hz}$ at Station STCD (Fig. 2a, c), consistent with the observations in Ballmer et al. (2013). Similar spectrum features can be seen in Station HAT, RIMD, and SDH near the Halema'uma'u crater and Station JCUZ and NPOC near the $\mathrm{Pu}^{\prime} \mathrm{u}^{\prime} \mathrm{O}^{\prime}{ }^{\prime} \mathrm{o}$ crater (Fig. 1 and Additional file 1: Figure S1). We use signals in a frequency band of $0.3-2.0 \mathrm{~Hz}$ (black boxes in Fig. 2) for the computation of $d v / v$. While the tremor signals are inevitably present in our analyzing band, compared to secondary microseism band they are generally stable over time except the February 2017 (Fig. 2c, d and Additional file 1: Figure S1b-e, f). The effect of tremor sources will be further discussed in "Noise sources" section.

The cross-correlation functions between stations are calculated with Welch's method (Seats et al. 2012) which cuts 1-day waveforms into 5-min moving time windows (75\% overlap) to improve the quality of correlation functions. A threshold of 1.5 root-mean-square ratio (RMSR, root mean square of amplitudes in 5-min time window divided by that in the entire 1-day period) is set to remove those RMSR $>1.5$ windows that contain unfavorable energetic signals (e.g., earthquakes, instrumental irregularities, and non-stationary transient signals). The rest of the time windows are spectrally whitened, calculated for 100-s time lag cross-correlation functions, and then stacked into a single representative NCF for the day. After daily NCFs are calculated, a further 10-day backward stacking for each day is applied to gain better coherence between NCFs. Stacking more days would increase NCF coherence but lower the time resolution of $\mathrm{d} v / v$ measurements. Coherence tests using a 30-s coda window at $6 \mathrm{~s}$ after the Rayleigh wave arrival with different stacking lengths are conducted for all three frequency bands and show that almost all coherence curves reach their plateau after 10 days of stacking (Additional file 1: Figures S2, S3). As an example, Fig. 3 shows the waveform coherency of the final NCFs for station pair DEVL-STCD across the entire analyzed period in three frequency bands. Except for February 2017 at $0.9-2.0 \mathrm{~Hz}$, the NCFs generally exhibit stable and high coherence until the eruption in May 2018 (green solid lines). A clear loss of waveform coherency can be seen after the eruption due to structural changes of magmatic system. The waveform coherency of all other station pairs is shown in Additional file 1: Figures S4-S34.

Next, the stretching method (Sens-Schönfelder and Wegler 2006) is adopted to measure $\mathrm{d} v / v$, by which the reference NCF ( $\mathrm{NCF}^{\mathrm{ref}}$ ) is either stretched or compressed to obtain the best fit $\mathrm{cc}(\varepsilon)$ with the current $\mathrm{NCF}\left(\mathrm{NCF}^{\mathrm{cur}}\right)$ via the equation

$$
\operatorname{cc}(\varepsilon)=\frac{\int_{t 1}^{t 2} \operatorname{NCF}^{\mathrm{cur}}(t) \mathrm{NCF}^{\mathrm{ref}}(t(1+\varepsilon)) d \mathrm{t}}{\int_{t 1}^{t 2}\left[\mathrm{NCF}^{\mathrm{cur}}(t)\right]^{2} \mathrm{~d} t \int_{t 1}^{t 2}\left[\mathrm{NCF}^{\mathrm{ref}}(t(1+\varepsilon))\right]^{2} \mathrm{~d} t}
$$

where $\varepsilon$ is a stretching factor, and $t_{1}$ and $t_{2}$ define the used time windows. By grid-searching $\varepsilon$ in a range of $-5 \%$ to $5 \%$ with a $0.005 \%$ interval ( 2000 trials), the $\mathrm{d} v / v$ is determined by the $\varepsilon$ which gives the highest correlation coefficient cc between the $\mathrm{NCF}^{\mathrm{cur}}$ and $\mathrm{NCF}^{\mathrm{ref}}$. A reference NCF is constructed by stacking daily NCFs over the entire period of 2017 . We compute $\mathrm{d} v / v$ in causal and anti-causal part of NCFs individually and average the results. For the station pairs with unstable $\mathrm{d} v / v$ fluctuations are excluded in the following analysis (e.g., Additional file 1: Figures S6, S9, S10, S21-S25).

\section{Depth sensitive kernel}

Assuming that the early codas of the NCFs are mainly composed of Rayleigh wave energy (Obermann et al. 2013b, 2016), we estimate the depth sensitivity of the three analyzed frequency bands using the computer program Surface85 (Herrmann 1987). Given a 1-D velocity model (Fig. 4a) averaged from a recent 3-D velocity model of the Kilauea area (Lin et al. 2014), the sensitivity kernels for shear wave velocity changes in different frequencies between 0.3 and $2.0 \mathrm{~Hz}$ are plotted as in Fig. 4b. The sensitivity of the lowest $(0.3-0.6 \mathrm{~Hz})$, middle $(0.6-0.9 \mathrm{~Hz})$, and the highest $(0.9-2.0 \mathrm{~Hz})$ frequency bands peaks at the depths around 1 to $2 \mathrm{~km}$, $500 \mathrm{~m}$ to $1 \mathrm{~km}$, and shallower than $500 \mathrm{~m}$ from surface, respectively.

\section{Uncertainty of detected $\mathrm{d} v / \mathrm{v}$}

Weaver et al. (2011) have proposed a theoretical formulation to estimate the root mean square (rms) of the apparent stretching factor $\varepsilon$ measured on two waveforms, which can be used as an error indicator of the estimated $\mathrm{d} v / v$ :

$$
\operatorname{rms} \varepsilon=\left(\frac{\sqrt{1-c c^{2}}}{2 c c}\right) \sqrt{\frac{6 \sqrt{\frac{\pi}{2}} T}{\omega_{\mathrm{c}}^{2}\left(t_{2}^{3}-t_{1}^{3}\right)}},
$$

where cc is the correlation coefficient value between the reference and current NCFs of station pairs, $T$ is the inverse of the measured frequency bandwidth, $\omega_{\mathrm{c}}$ is the central frequency of the measured frequency band, and $t_{1}$ and $t_{2}$ are the beginning and the end time of the processing coda time window. The errors are computed for causal and anti-causal part of NCFs individually and averaged (Fig. 5b and Additional file 1: Figures S4-S34). 

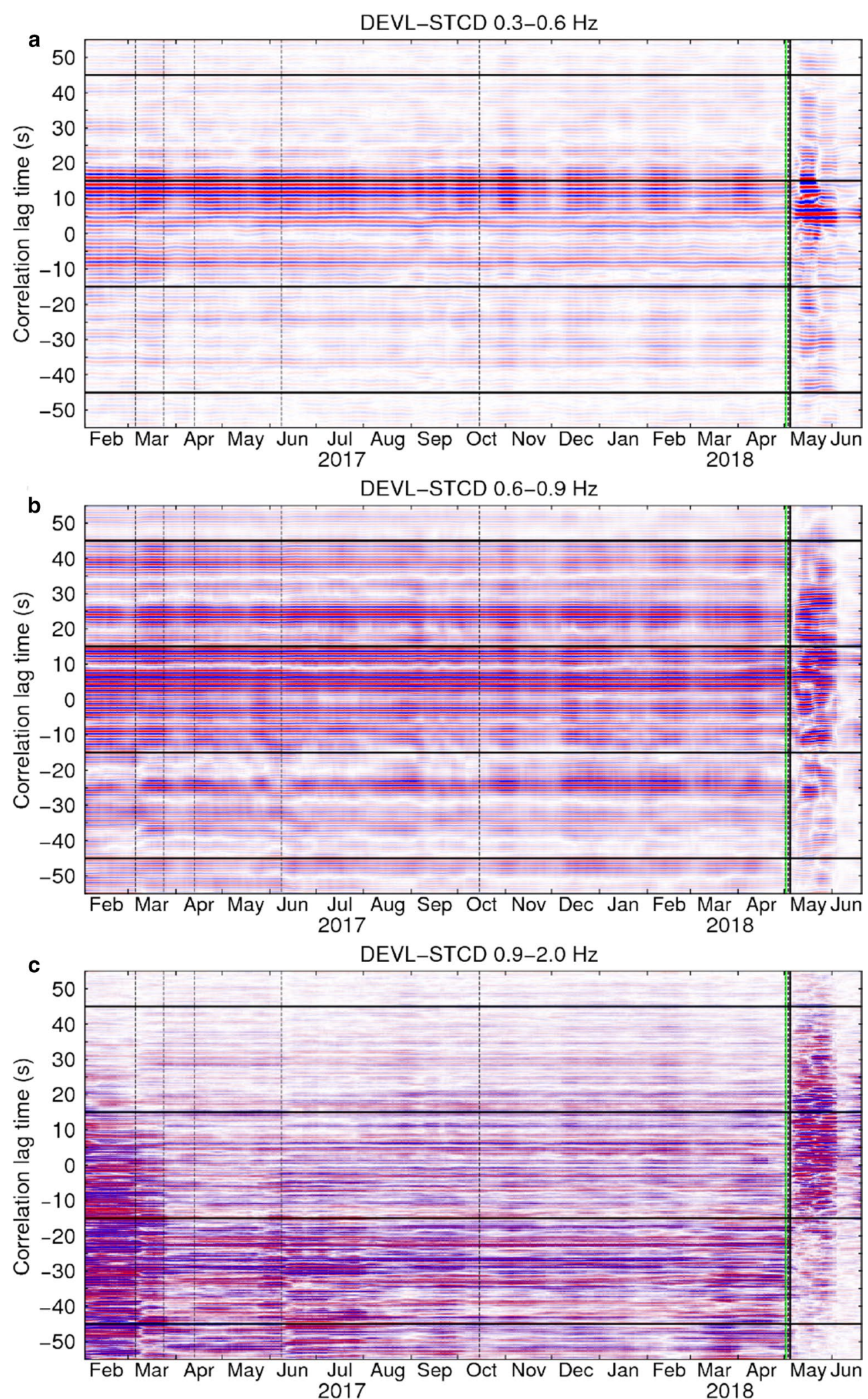

Fig. 3 Daily cross-correlation functions for station pair DEVL-STCD. a $0.3-0.6 \mathrm{~Hz}$. b $0.6-0.9 \mathrm{~Hz}$. c $0.9-2.0 \mathrm{~Hz}$. Black boxes denote the used coda windows. Vertical dashed lines show the occurrence times of the earthquakes $(M \geq 3.5)$ before the greatest one $\left(M_{w} 6.9\right.$ earthquake on May 4). The green line marks the beginning time of the 2018 eruption 


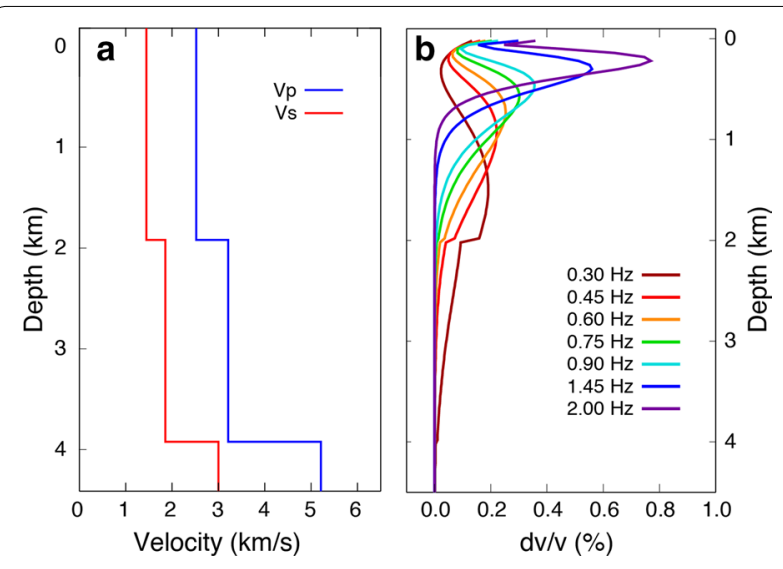

Fig. 4 The 1-D velocity model and corresponding Rayleigh-wave depth sensitivity kernels. a The P-wave (blue) and S-wave (red) 1-D velocity models of Kilauea area averaging from the 3-D velocity model (Lin et al. 2014). b Rayleigh-wave depth sensitivity kernels for shear wave velocity changes in different frequencies between 0.3 and $2.0 \mathrm{~Hz}$

\section{Results and discussion \\ Noise sources}

A stable distribution of background noise sources is one of the most important requirements for using ANI to estimate relative velocity changes (Campillo and Paul 2003; Hadziioannou et al. 2009). In the Kilauea area, the volcanic tremors generated by lava lake spattering are well-recognized signals constantly present in the frequencies of $0.3-0.8 \mathrm{~Hz}$ at the Halema'uma'u crater and above $0.8 \mathrm{~Hz}$ at the $\mathrm{Pu}^{\prime} \mathrm{u}^{\prime} \mathrm{O}^{\prime} \mathrm{o}$ crater (Patrick et al. 2016a, b; Ballmer et al. 2013), as observed in Fig. 2 and Additional file 1: Figure S1. But first, except for few stations around $\mathrm{Pu}^{\prime} \mathrm{u}^{\prime} \mathrm{O}^{\prime} \mathrm{o}$ crater showing relatively stronger energy fluctuations in the frequencies above $0.8 \mathrm{~Hz}$ (Fig. 2c and Additional file 1: Figure S1c, e), these tremor signals seem persistent and stable for most of the stations over the study time period. Second, these tremors are generated within the top part of the magma column from lake surface to $\sim 1 \mathrm{~km}$ depth (Patrick et al. 2016a, b). Since this migration distance is small compared to the length scale of the station pair distance we analyzed, the tremor sources can be reasonably treated as stationary sources. They therefore contribute to the cross-correlation as stable energy sources in the region and unlikely bias the $\mathrm{d} v / v$ measurements for the long-distance station pairs used mostly in this study. The effect of tremor migration is probably more significant for short-distance pairs so the crossing pairs around the Halema'uma ' $u$ and $\mathrm{Pu}^{\prime} \mathrm{u}^{\prime} \mathrm{O}^{\prime} \mathrm{o}$ craters are removed from later $\mathrm{d} v / v$ analysis.

The seasonality of ocean noise could be another potential source of $\mathrm{d} v / v$ errors. However, the seasonal variations in noise energy are seen strongest in $0.1-0.3 \mathrm{~Hz}$
(Figs. 2 and 5d). In the analyzed frequency band of $0.3-2 \mathrm{~Hz}$, the temporally stable noise energy (Fig. 2), high coherency of NCFs over time (Fig. 3 and Additional file 1: Figures S4-S34), and estimated $\mathrm{d} v / v$ not showing related seasonable patterns (Figs. 5 and 6) suggest that the influence from ocean noise seasonality is not significant. Also, Eq. 3 should in principle account for such errors if present, and the estimated errors are generally lower than the $\mathrm{d} v / v$ variations discussed later in the study (Fig. $5 \mathrm{~b}$ and Additional file 1: Figures S4d-S34d).

\section{Estimated seismic velocity variations ( $d v / v)$}

The time evolution of estimated $\mathrm{d} v / v$ results and corresponding cc values are shown in Fig. 6 . For the lower two frequency bands (Fig. 6c-f), the cc values are stable and above 0.85 most of the time (Fig. 6c, e); for the highest one, the cc values are relatively lower but still above 0.7 except for the February 2017 (Fig. 6a). The variations of $\mathrm{d} v / v$ show similar trend for all three frequency bands in 2017 with two velocity drops in March and June (Grayish shaded zones in Fig. 6). These $\mathrm{d} v / v$ drops are most obvious in the frequency bands of $0.6-0.9 \mathrm{~Hz}$ and $0.9-2.0 \mathrm{~Hz}$. On the other hand, clear $\mathrm{d} v / v$ excursions either negative or positive, with slightly decreasing cc values, begin at the end of 2017 for the lowest frequency band $(0.3-0.6 \mathrm{~Hz})$. The $\mathrm{d} v / v$ in the higher two frequency bands wait until the mid-March 2018 to start to gradually increase. At the end of April, the $\mathrm{d} v / v$ in all frequency bands drop rapidly to the eruption on May 2.

To investigate the mechanism of these distinct $\mathrm{d} v / v$ features, we use the station pair DEVL-STCD as a representative to demonstrate and compare the estimated $\mathrm{d} v / v$ with daily seismic amplitude RMS of each station in different frequency bands, daily peak ground velocity (PGV), and daily earthquake number (Fig. 5). Results for all station pairs are displayed in Additional file 1: Figures S4-S34. In Fig. $5 \mathrm{c}-\mathrm{e}$, the $0.01-0.1 \mathrm{~Hz}$ and $0.3-$ $2.0 \mathrm{~Hz}$ are the frequency bands related to the first and second type of volcanic tremors (Patrick et al. 2011; Dawson and Chouet 2014; Patrick et al. 2016a, b) and the 0.1$0.3 \mathrm{~Hz}$ represents the secondary microseism frequency band. We also mark the origin times (grayish dashed lines in Fig. 5) of 16 M 3.5 earthquakes (focal depth less than $10 \mathrm{~km}$ ) occurring in the Kilauea area prior to the $M_{\mathrm{w}} 6.9$ earthquake on May 4 (Fig. 1 and Additional file 1: Table S1). It is clear that the two seismic velocity drops in 2017 appear immediately after the earthquakes No. 1-3 (they occurred closely within one day, see Fig. 1 for the locations) and No. 6 (the largest event in the Kilauea area in 2017). These two sets of earthquakes are also the ones that produce the largest PGV (Fig. 5f) and amplitude RMS in our studied frequency band (Fig. 5c), indicating a correlation to the strong ground shaking of 


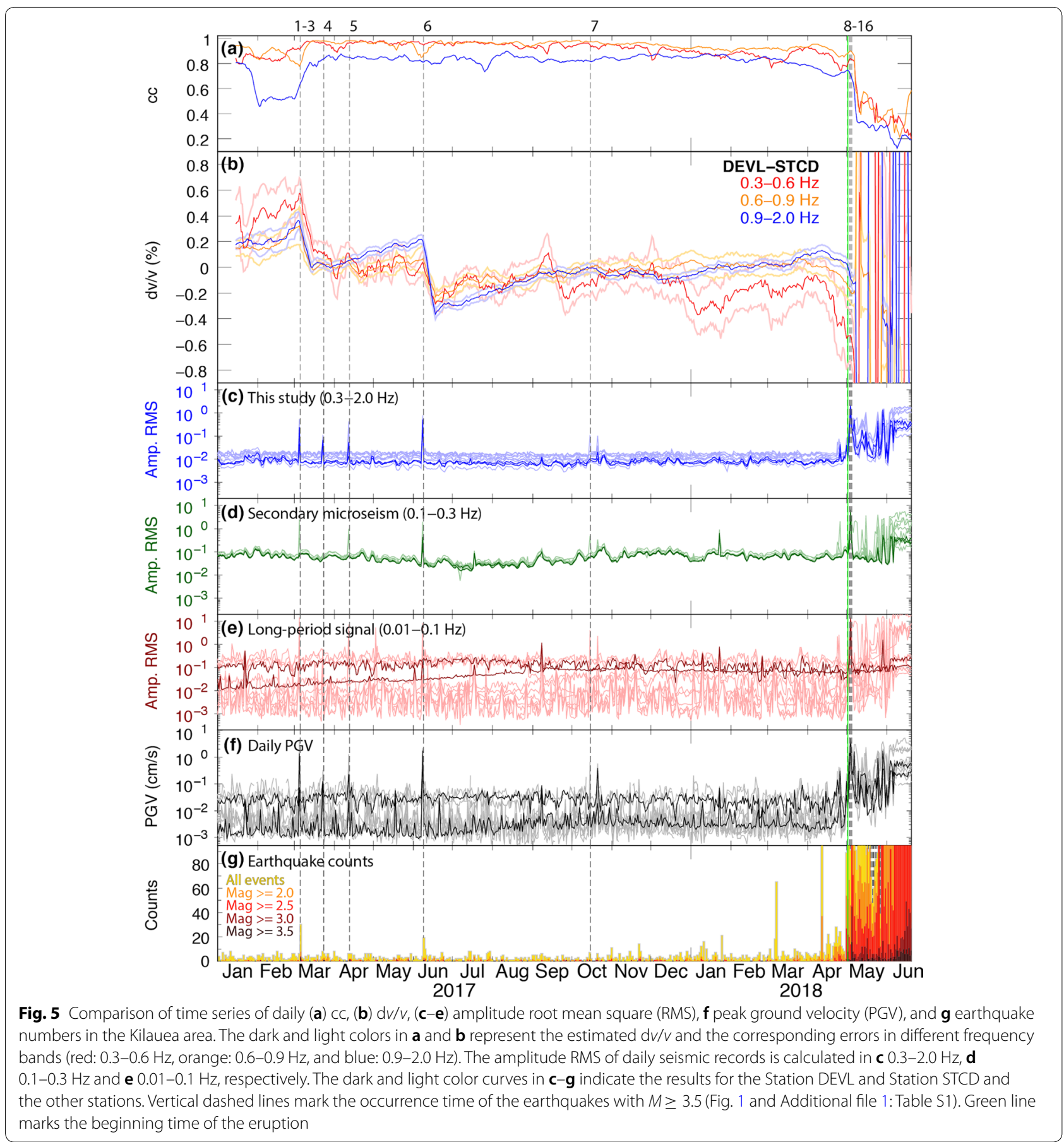

earthquakes. Figure 7 further shows the spatial distribution of the two $\mathrm{d} v / v$ drops, where the station pairs closer to the epicenters (gray dots) show greater drops of $\mathrm{d} v / v$ (warmer colors). For Earthquake No. 6 (Fig. 7d-f), the much greater $\mathrm{d} v / v$ drops occur in the higher two frequency bands of $0.6-0.9 \mathrm{~Hz}$ and $0.9-2.0 \mathrm{~Hz}$, suggesting that the shaking-induced medium changes occur mostly in the uppermost $1 \mathrm{~km}$ of the crust based on the depth sensitivity kernels shown in Fig. 4b. This may result from in situ cracks of the shallow crustal layer being temporally increased or opened during dynamic ground shaking and gradually recovered by the crack closure and re-compaction over time (Brenguier et al. 2014; Taira et al. 2015, 2018). Similarly, for Earthquake No. 1-3 (Fig. $7 \mathrm{a}-\mathrm{c}$ ), the $\mathrm{d} v / v$ reductions are also larger in the higher two frequency bands. 

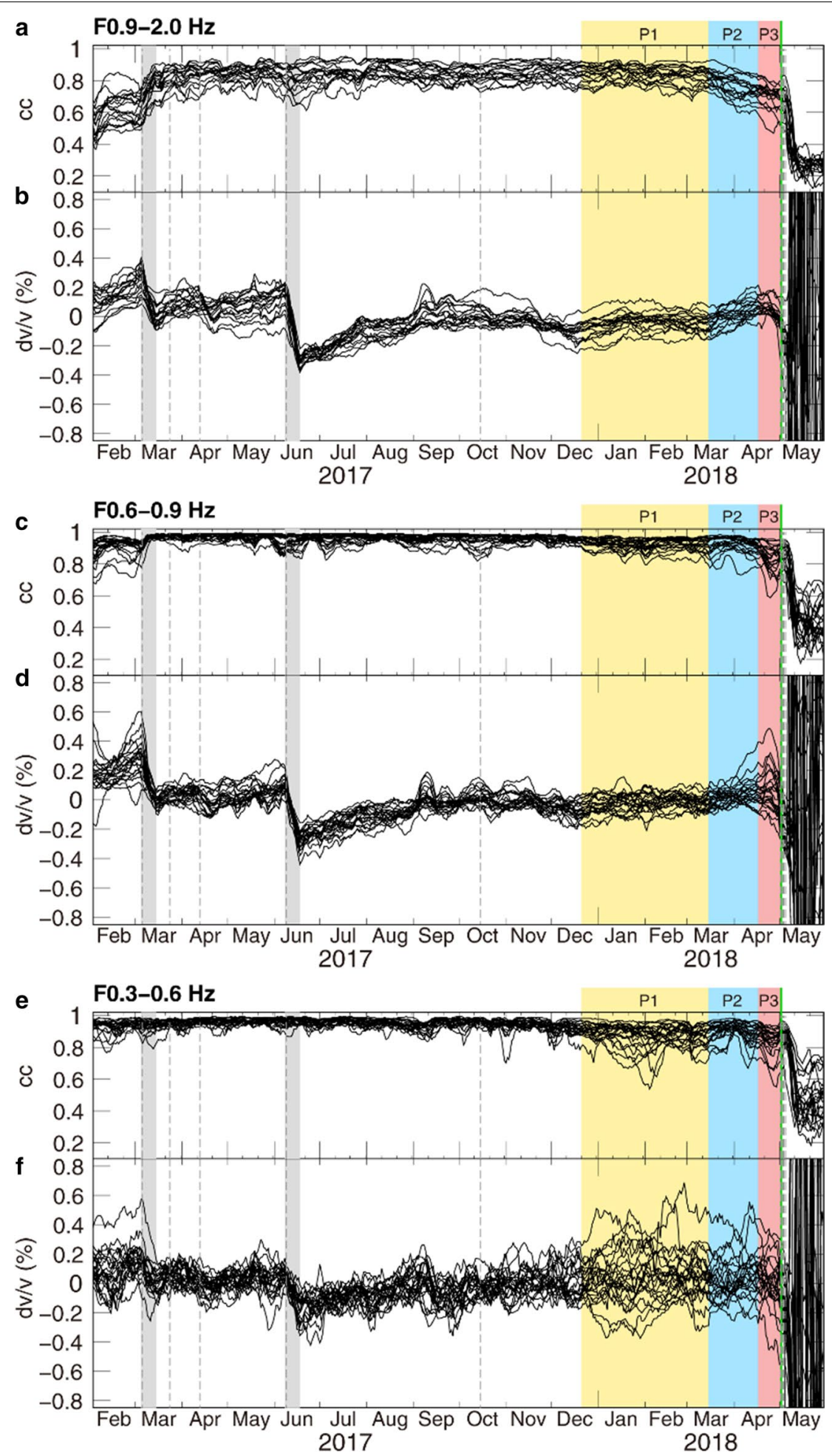

Fig. 6 Time series of $\mathrm{cc}$ values and estimated $\mathrm{d} v / \mathrm{v}$ in three frequency bands. a, b $0.9-2.0 \mathrm{~Hz}$. c, d $0.6-0.9 \mathrm{~Hz}$. e, $\mathbf{f}$ 0.3-0.6 Hz. Grayish shaded zones mark 10 days following the occurrence time of earthquake No. 1-3 and No. 6. Yellowish shaded zone represents Period 1 (P1, from December 20, 2017 to March 15, 2018). Bluish shaded zone represents Period 2 (P2, from March 15, 2018 to April 17, 2018). Reddish shaded zone represents Period 3 (P3, from April 17, 2018 to May 1, 2018). Dashed lines mark the occurrence times of earthquakes shown in Fig. 1. Green lines after P3 mark the May 2 eruption near Leilani Estates 


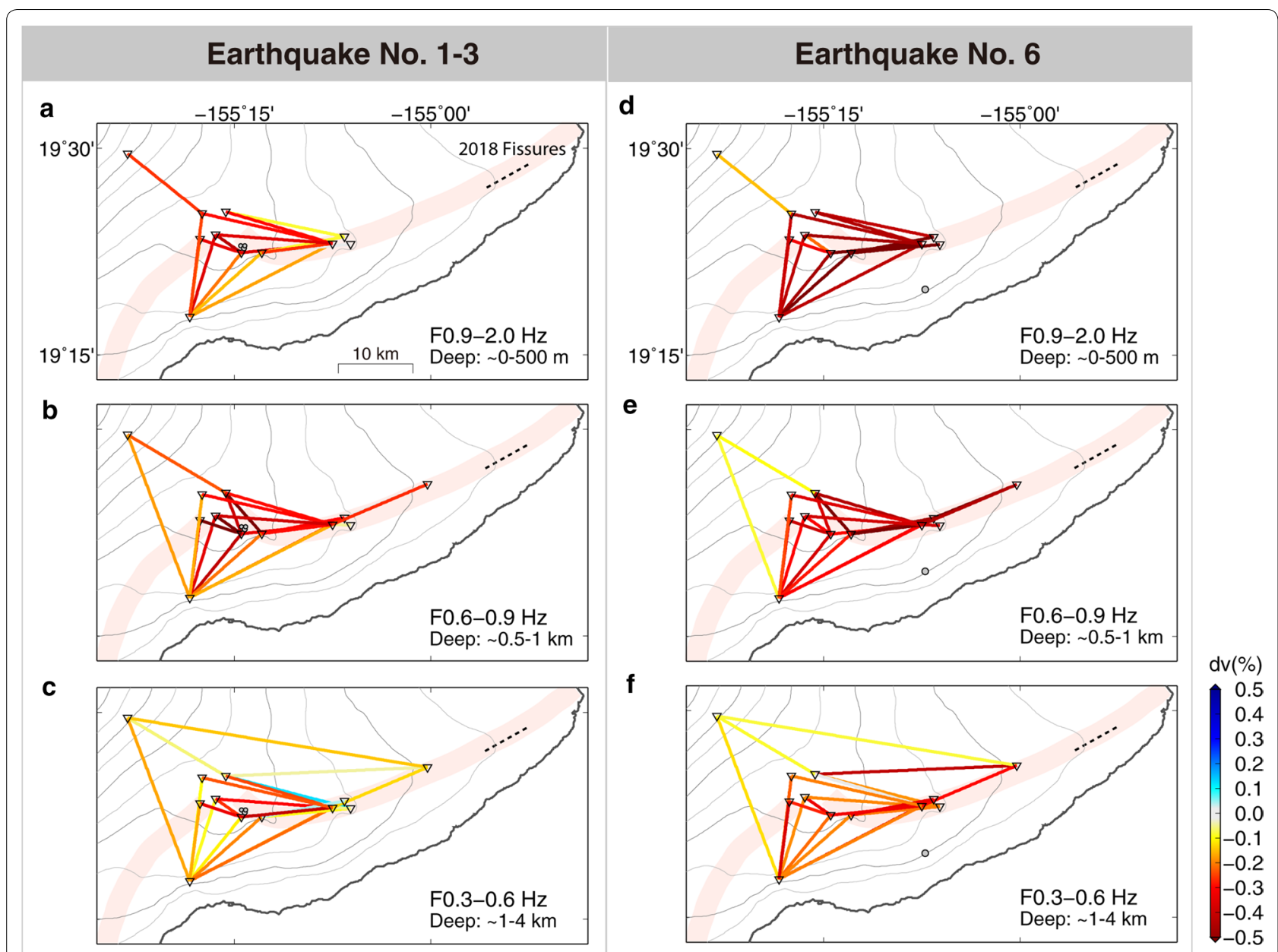

Fig. 7 Map of co-seismic dv/v drops in three frequency bands. a-c The earthquake No. 1-3. d-f the earthquake No. 6. The dv/v values are shown in lines between stations and color-coded by the difference within 10 days after the earthquake (grayish shaded zones in Fig. 5). The black dashed line indicates the fissures opened during the 2018 eruption

For the $\mathrm{d} v / v$ excursion that occurs in late December 2017, we confirm that no significant changes in either noise signals (Figs. 2b, c and $5 \mathrm{c}-\mathrm{f}$ ) or seismicity (Fig. 5g) observed around the time so the excursion is likely related to the actual medium changes. Also, this excursion that appears most obviously in the lowest frequency band and little in the higher two suggests the medium changes at a depth range of 1-4 km according to the sensitivity kernel calculation (Fig. 4b). This depth range well corresponds to depths of reservoirs at summit and the top of the dike system along the ERZ (Heliker et al. 2003; Poland et al. 2014; Pietruszka et al. 2015), we therefore speculate that probable pre-eruptive magmatic intrusion processes responsible for the $\mathrm{d} v / v$ excursion beginning from the end of 2017.

\section{The long-term $\mathrm{d} v / v$ excursion and magmatic intrusion processes}

The long-term $\mathrm{d} v / v$ excursions mainly in the frequency band of $0.3-0.6 \mathrm{~Hz}$ can form into two groups: one shows negative $\mathrm{d} v / v$ excursions as the station pair DEVL-STCD (Fig. 5) and NPOC-PAUD (Additional file 1: Figure S26); and the other shows positive as the station pair HATJOKA (Additional file 1: Figure S10) and HLPD-PAUD (Additional file 1: Figure S16) for reference. Based on the temporal characteristics of $\mathrm{d} v / v$, we divide this excursion time into three periods for further investigation (Fig. 6): (1) Period 1 comprises the first stage of long-term $\mathrm{d} v / v$ excursion that is only observed in the frequency band of 0.3-0.6 Hz (December 20, 2018 to March 15, 2018); (2) Period 2 is when the summit tiltmeters start to record inflationary ground deformation to the first pressurization issue at $\mathrm{Pu}^{\prime} \mathbf{u}^{\prime} \mathrm{O}^{\prime}$ ō called by HVO (March 152018 to April 17, 2018); (3) Period 3 is the time after the first 


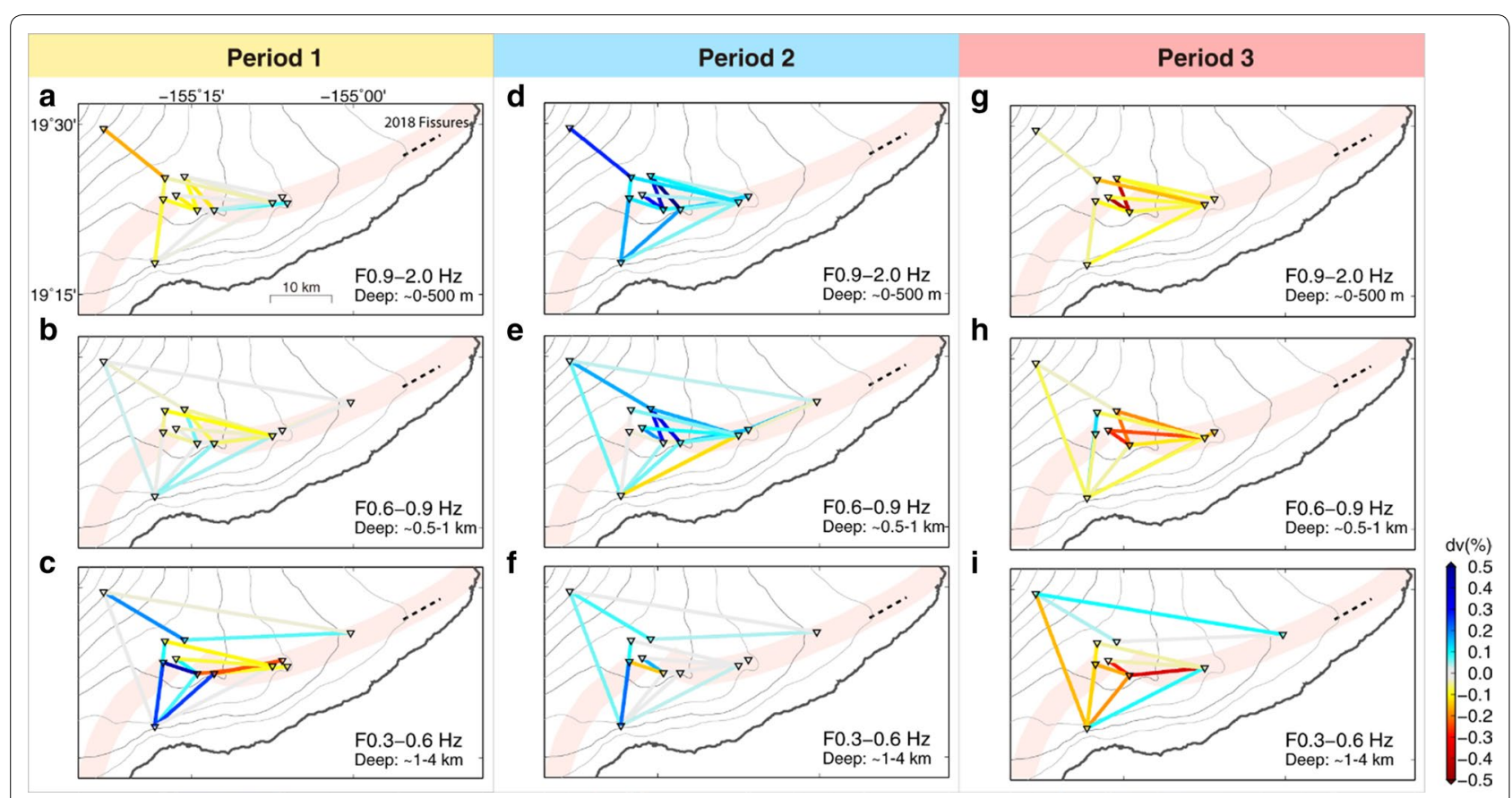

Fig. 8 Map of frequency-dependent magma-related $d v / v$ changes in three time periods marked in Fig. 5. a-c Period 1. d-f Period 2. g-i Period 3. In Period 1, the $\mathrm{d} v / v$ values are color-coded by averaging $\mathrm{d} v / v$ values between January 1, 2018 and March 15, 2018 (yellowish shaded zone in Fig. 5). In Period 2, the $\mathrm{d} v / v$ values are color-coded by subtracting $\mathrm{d} v / v$ value on March 15, 2018 from that on April 17, 2018 (bluish shaded zone in Fig. 5). In Period 3, the $d v / v$ values are color-coded by subtracting $d v / v$ value on April 17, 2018 from that on May 1, 2018 (reddish shaded zone in Fig. 5). The black dashed line indicates the fissures opened during the 2018 eruption

pressurization issue at $\mathrm{Pu}^{\prime} \mathrm{u}^{\prime} \mathrm{O}^{\prime} \mathrm{o}$ until the day before the LERZ eruption (April 17, 2018 to May 1, 2018).

\section{Phase 1: deep magma intrusion}

In Period 1 (yellowish shaded zone in Fig. 6), we plot the $\mathrm{d} v / v$ of station pairs in lines color-coded by averaging the $\mathrm{d} v / v$ values from January 1 to March 15,2018 . Warm and cold colors indicate negative and positive average values of $\mathrm{d} v / v$ (Fig. $8 \mathrm{a}-\mathrm{C}$ ). As shown in Fig. 6, the $\mathrm{d} v / v$ variations in higher two frequency bands are small (light color in Fig. 8a, b). The main feature of $\mathrm{d} v / v$ in Period 1 appears only in the lowest frequency band where the $\mathrm{d} v / v$ decreases mainly for the station pairs from the Kilauea summit to the Pu' ${ }^{\prime}{ }^{\prime} \mathrm{O}^{\prime}$ ô crater (along the UERZ) but increases for the pairs in the surrounding regions (Fig. 8c). In particular, the station pair DEVL-STCD right along the UERZ decreases most down to -0.3 (Fig. 5). Its cc values also start to slightly decrease around the same time from December 2017. While a number of causes can influence the cc values, the coincident timing with the $\mathrm{d} v / v$ excursion and relatively stable background noise at the times (Figs. 3 and 5c) may suggest structural changes related to the deep magmatic processes (Obermann et al. 2013a; Bennington et al. 2015). The depth of such processes could be reasonably put at the depths of
1-4 km since the sensitivity of the higher two frequency bands is mainly within top $1 \mathrm{~km}$ and that of $0.3-0.6 \mathrm{~Hz}$ bottoms at $4 \mathrm{~km}$ (Fig. 4b).

The dike-like magma reservoir along the ERZ has been suggested to top at $\sim 3 \mathrm{~km}$ from the decollement of $9 \mathrm{~km}$ in previous studies (Delaney et al. 1990; Cayol et al. 2000; Heliker et al. 2003; Poland et al. 2014). A narrow ribbon of precisely relocated seismicity at $\sim 3-\mathrm{km}$ depth was interpreted to mark a highly stressed zone corresponding to the intrusion of dikes (Gillard et al. 1996; Rubin et al. 1998). The limited vertical extent of these seismicity suggests that the stress or strain changes are concentrated around the tip of the deforming dike. The observed strong $\mathrm{d} v / v$ decreases for the station pair DEVL-STCD likely reflect a stress/volumetric strain change at such localized zone atop the dike tip caused by the magmatic intrusion activities (3-D illustration in Fig. 9a, c). As a connecting magmatic plumbing system, the intrusion likely also feeds in the deeper magma reservoir at the summit (reservoir $\mathrm{SC}$ in cross-section $\mathrm{AB}$ ) and results in the spatial distribution of $\mathrm{d} v / v$ decreases mainly between the Kilauea summit and $\mathrm{Pu}^{\prime} \mathrm{u}^{\prime} \mathrm{O}^{\prime} \mathrm{o}$ area; but at the same time the inflation of the dike and reservoir also compresses the surrounding medium and causes the $\mathrm{d} v / v$ increases in the surrounding regions of the summit and 


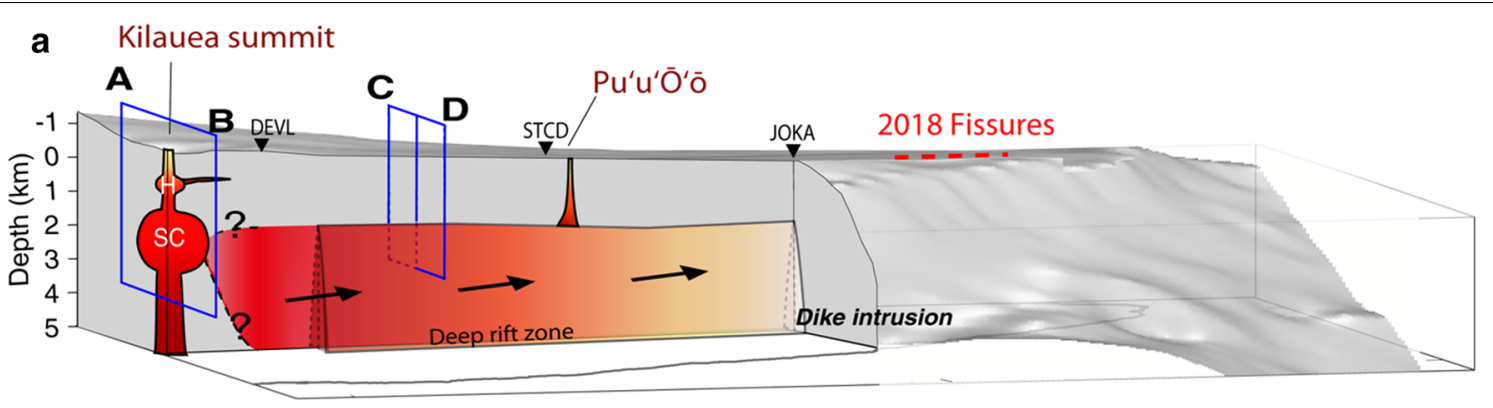

P1 - deep magma intrusion

b

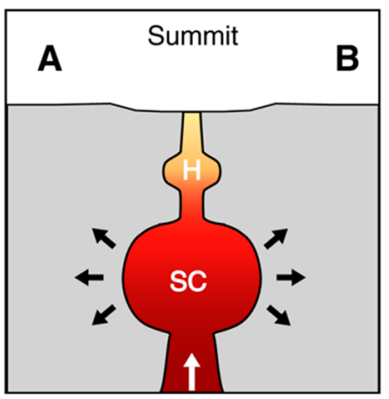

c

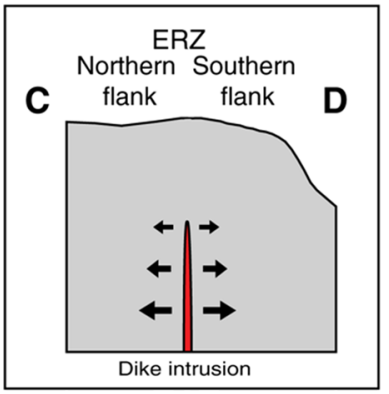

P2 - summit inflation

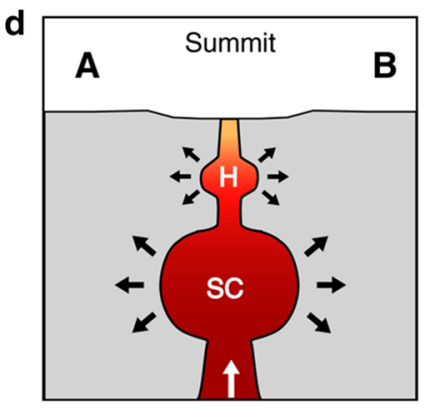

e

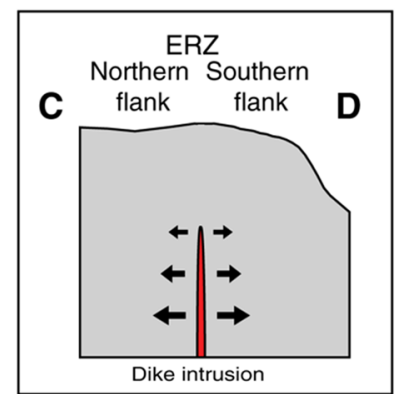

P3 - damage accumulation

f

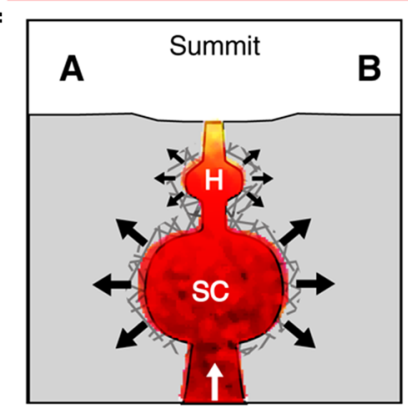

g

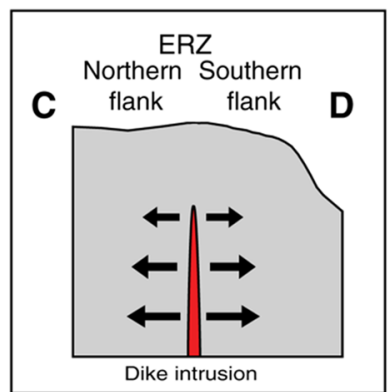

Fig. 9 Schematic model of proposed magmatic processes prior to the 2018 eruption. a 3-D illustration of magmatic reservoir-dike system in the Kilauea area. $\mathbf{b}$ Cross-section A-B and $\mathbf{c} C-D$ illustrate the time evolution of proposed processes at the summit and across the UERZ in the three periods as blue boxes in $\mathbf{a}$. H, Halema'uma'u reservoir; SC, Southern caldera reservoir. P1, P2, and P3 denote the time periods of deep magma intrusion, summit inflation, and damage accumulation of edifice. Please refer to the details in the text

the rift zone (Figs. 8c, 9b, c). The insignificant seismic velocity variations in the $0.6-0.9 \mathrm{~Hz}$ and $0.9-2.0 \mathrm{~Hz}$ frequency bands imply that such magmatic process mainly caused localized stress/strain changes at limited depth range below $1 \mathrm{~km}$. This may also explain why the magmatic process showed little effect on the surface to be geodetically detected before the mid-March 2018 (Neal et al. 2019).

\section{Phase 2: summit inflation}

When the summit starts to inflate from the mid-March 2018 (Period 2, bluish shaded zone in Fig. 6), the $d v / v$ in the higher two frequency bands show gradual increases correspondingly (Fig. 6b, c). For this period, we change to plot the $d v / v$ of station pairs by subtracting the $d v / v$ value on March 15, 2018 from that on April 17, 2018 to emphasize the relative velocity changes so zero values mean that the $\mathrm{d} v / v$ remain the same with Period 1 . In this way, we see the $\mathrm{d} v / v$ in the higher two frequency bands clearly increasing for the station pairs at the summit and surroundings (Figs. $8 \mathrm{~d}, \mathrm{e}$ ), whereas the $\mathrm{d} v / v$ in the lowest frequency band are small in general and suggest a similar sate of the deep magmatic intrusion processes (Figs. $8 \mathrm{f}$ and 9e). This pattern implies that the magma has intruded into and inflates the shallower magma reservoir at this time as recorded by tiltmeter and GPS at summit (Fig. 9d). Moreover, these intrusion/inflation processes of the shallow magma reservoir are also evidenced by the decrease of cc values in two higher frequency bands, a sign of structural changes (Fig. 6a, c). 


\section{Phase 3: damage accumulation}

After April 17, 2018 when the HVO issued notice of the pressurization at the $\mathrm{Pu}^{\prime} \mathbf{u}^{\prime} \mathrm{O}^{\prime} \mathrm{o}$ crater (Period 3, reddish shaded zone in Fig. 6), while a few station pairs in the $0.6-0.9 \mathrm{~Hz}$ frequency band exhibit a short increase on first few days, most of station pairs start to decrease monotonically to the eruption time in all frequency bands (Fig. 6). In Fig. $8 \mathrm{~g}-\mathrm{i}$, the $\mathrm{d} v / v$ of the station pairs are again computed by subtracting the $\mathrm{d} v / v$ value on April 17, 2018 from that on May 1, 2018 in a relative velocity sense. For the lowest frequency band, the $\mathrm{d} v / v$ decreases from the summit to the $\mathrm{Pu}^{\prime} \mathrm{u}^{\prime} \overline{\mathrm{O}}^{\prime} \mathrm{o}$ area and strongest along the rift zone, indicating that the deep magmatic intrusion processes become amplified. Two $\mathrm{d} v / v$ increasing pairs in the north and south are then in response to the crustal compression from the dike inflation (Figs. $8 \mathrm{i}$ and 9g). In contrast, the $\mathrm{d} v / v$ for the station pairs around the summit show decreases but not increases as in Period 1 (Fig. 8c, i). The $\mathrm{d} v / v$ in the higher two frequency bands also show general decreases around the summit this time (Fig. 8g, h). This decreasing pattern of $\mathrm{d} v / v$, however, contradicts to the amplification of magmatic intrusion aforementioned and also the continued inflationary deformation recorded by tiltmeters at the summit (Olivier et al. 2019). One possible explanation proposed by Olivier et al. (2019) is the accumulating damage induced by the pressure exerted by the magma reservoir on the edifice (Fig. 9f). In this weakening process, while the surface deformation keeps inflationary, the edifice strength and magma reservoir pressure both decrease with decreasing elastic moduli (Carrier et al. 2015). As a result, it leads to the decrease in seismic velocity and may have facilitated the eastward transport of magma into the rift zone, as amplified $\mathrm{d} v / v$ decrease observed in the UERZ in Fig. 8i.

At the end of April, a burst of seismicity occurred and propagated from the $\mathrm{Pu}^{\prime} \mathrm{u}^{\prime} \mathrm{O}^{\prime} \mathrm{o}$ crater toward its lower flank. Most likely, these earthquakes initiate the rupturing of a barrier in the MERZ, which allows substantial volume of magma to move into the LERZ and lead to the eruption on May 2, 2018. All derived $\mathrm{d} v / v$ then strongly oscillate after the eruption because of the severe loss of NCF coherency due to strong structural change and the boost of earthquake activity (Figs. $5 \mathrm{~g}$ and 6 ).

\section{Precursory changes in $d v / v$ of volcano eruptions}

The precursory changes in seismic velocity have been found at some volcanoes in recent decades (Brenguier et al. 2008; Obermann et al. 2013a; Budi-Santoso and Lesage 2016; Olivier et al. 2019). At PdF volcano, for example, the precursor time of seismic velocity changes is about few weeks ahead of eruptions (Brenguier et al. 2008). At Kilauea volcano, here we find a longer precursory phase of several months prior to the LERZ eruption.
However, $\mathrm{d} v / v$ precursors are not always observed. At Mt. Enta for instance, recent studies showed no significant $\mathrm{d} v / v$ precursors to be detected preceding the eruptions (Cannata et al. 2017; De Plaen et al. 2019). Although the used frequency bands and preprocessing methods also matter, such variability of precursory $\mathrm{d} v / v$ observations may imply that different types of volcanic eruptions (i.e., explosive, strombolian, and effusive eruptions) have varying precursor times from little to several months in response to their different magmatic processes. Our results suggest a long precursory phase of about 6 months for the Kilauea basaltic shield volcano.

\section{Conclusions}

We analyze one-and-half year seismic data with ambient noise interferometry (ANI) to investigate pre-eruptive magmatic processes of the 2018 Kilauea eruption. With careful inspections on correlation quality, noise source, and error estimation, we find two earthquake-induced $\mathrm{d} v / v$ drops in 2017 and a magma-related long-term $\mathrm{d} v / v$ excursion beginning from the December 2017 (Figs. 5 and 6). The magma-related process comprises three main periods of activity based on the temporal $\mathrm{d} v / v$ characteristics (Figs. 8 and 9). From the December 2017 to midMarch 2018 (Period 1), the magmatic intrusion began to take place in the deeper magma reservoir at summit and in the dikes along the UERZ so mainly influenced the $\mathrm{d} v / v$ in the lowest frequency band. From March 15 to April 17, 2018, the intrusion process reached the shallow magma reservoir and caused sensible summit inflation recorded by tiltmeters and increases in $\mathrm{d} v / v$ around the summit. After April 17 to the eruption (Period 3), the magmatic intrusion was amplified and caused the accumulating damaging of the edifice, which then results in $\mathrm{d} v / v$ decreases around the summit and UERZ. As a result, our results suggest a long precursory phase to the Kilauea volcano eruption beginning from the December 2017, with three distinct stages showing progression and interaction of the reservoir-dike magmatic system. The analysis demonstrates the strength of using ANI with multiple frequency bands to gain better depth and spatial information to imaging pre-eruptive magmatic processes over time and can be a useful supplement to current volcanic monitoring systems for eruption warnings and hazard prevention.

\section{Supplementary information}

Supplementary information accompanies this paper at https://doi. org/10.1186/s40623-020-01199-x.

Additional file 1. Additional figures and table. 


\section{Abbreviations}

ANI: Ambient noise interferometry; dv/v: Seismic velocity change; ERZ: East Rift Zone; HVO: The Hawaiian Volcano Observatory; LERZ: Lower East Rift Zone; MERZ: Middle East Rift Zone; UERZ: Upper East Rift Zone.

\section{Acknowledgements}

We thank Mong-Han Huang, Fan-Chi Lin, and Sin-Mei Wu for valuable discussion and suggestions. We also thank the editor Mare Yamamoto and two reviewers Nori Nakata and Gerrit Olivier for their constructive comments which substantially improve the work. The waveform data were from the Incorporated Research Institutions for Seismology and the earthquake information were from the United States Geological Survey.

\section{Authors' contributions}

$\mathrm{KF}$ and $\mathrm{HH}$ designed this study, conducted the analyses, and drafted the manuscript. YW contributed to the discussion and drafting. All authors read and approved the final manuscript.

\section{Funding}

This work was supported by Ministry of Science and Technology Grant MOST 107-2923-M-001-006-MY3.

\section{Availability of data and materials}

The seismic data used in this study were downloaded from the Incorporated Research Institutions for Seismology (https://ds.iris.edu/ds/nodes/dmc/forms/ breqfast-request/). The earthquake catalog is from the United States Geological Survey website (https://earthquake.usgs.gov/earthquakes/search/).

\section{Competing interests}

The authors declare that they have no competing interests.

\section{Author details}

${ }^{1}$ Department of Geosciences, National Taiwan University, Taipei 10617, Taiwan.

${ }^{2}$ Institute of Earth Sciences, Academia Sinica, Taipei 11529, Taiwan.

Received: 29 February 2020 Accepted: 18 May 2020

Published online: 30 May 2020

\section{References}

Anggono T, Nishimura T, Sato H, Ueda H, Ukawa M (2012) Spatio-temporal changes in seismic velocity associated with the 2000 activity of Miyakejima volcano as inferred from cross-correlation analyses of ambient noise. J Volcanol Geotherm Res 247:93-107. https://doi.org/10.1016/j.jvolgeores .2012.08.001

Ballmer S, Wolfe CJ, Okubo PG, Haney MM, Thurber CH (2013) Ambient seismic noise interferometry in Hawai'i reveals long-range observability of volcanic tremor. Geophys J Int 194(1):512-523. https://doi.org/10.1093/ gji/ggt112

Bennington NL, Haney M, De Angelis S, Thurber CH, Freymueller J (2015) Monitoring changes in seismic velocity related to an ongoing rapid inflation event at Okmok volcano, Alaska. J Geophys Res Solid Earth 120:5664-5676. https://doi.org/10.1002/2015jb011939

Bennington N, Haney M, Thurber C, Zeng X (2018) Inferring magma dynamics at Veniaminof volcano via application of ambient noise. Geophys Res Lett 45(21):11650-11658. https://doi.org/10.1029/2018gl079909

Brenguier F, Shapiro N, Campillo M, Ferrazzini V, Duputel Z, Coutant O, Nercessian A (2008) Towards forecasting volcanic eruptions using seismic noise. Nat Geosci 1:126-130. https://doi.org/10.1038/ngeo104

Brenguier F, Campillo M, Takeda T, Aoki Y, Shapiro N, Briand X, Emoto K, Miyake $H$ (2014) Mapping pressurized volcanic fluids from induced crustal seismic velocity drops. Science 345(6192):80-82. https://doi.org/10.1126/ science. 1254073

Budi-Santoso A, Lesage P (2016) Velocity variations associated with the large 2010 eruption of Merapi volcano, Java, retrieved from seismic multiplets and ambient noise cross-correlation. Geophys J Int 206(1):221-240. https ://doi.org/10.1093/gji/ggw145

Campillo M, Paul A (2003) Long-range correlations in the diffuse seismic coda. Science 299:547-549. https://doi.org/10.1126/science.1078551
Cannata A Cannavò F Montalto P. Ercoli M, Mancinelli P, Pauselli C, Leto G (2017) Monitoring crustal changes at volcanoes by seismic noise interferometry: Mt. Etna case of study. J Volcanol Geotherm Res 337:165-174. https://doi.org/10.1016/j.jvolgeores.2017.03.023

Carrier A, Got JL, Peltier A, Ferrazzini V, Staudacher T, Kowalski P, Boissier P (2015) A damage model for volcanic edifices: implications for edifice strength, magma pressure, and eruptive processes. J Geophys Res Solid Earth 120(1):567-583. https://doi.org/10.1002/2014jb011485

Cayol V, Dieterich JH, Okamura AT, Miklius A (2000) High magma storage rates before the 1983 eruption of Kilauea, Hawaii. Science 288:2343-2346. https://doi.org/10.1126/science.288.5475.2343

Chen K, Smith JD, Avouac JP, Liu Z, Song YT, Gualandi A (2019) Triggering of the Mw 7.2 Hawaii Earthquake of 4 May 2018 by a Dike Intrusion. Geophys Res Lett 46(5):2503-2510. https://doi.org/10.1029/2018gl081428

Colombi A, Chaput J, Brenguier F, Hillers G, Roux P, Campillo M (2014) On the temporal stability of the coda of ambient noise correlations. CR Geosci 346(11-12):307-316. https://doi.org/10.1016/j.crte.2014.10.00

Dawson P, Chouet B (2014) Characterization of very-long-period seismicity accompanying summit activity at Kïlauea Volcano, Hawai'i: 2007-2013. Volcanol Geotherm Res 278:59-85. https://doi.org/10.1016/j.jvolgeores .2014.04.010

De Plaen RS, Cannata A, Cannavo F, Caudron C, Lecocq T, Francis O (2019) Temporal changes of seismic velocity caused by volcanic activity at Mt. Etna revealed by the autocorrelation of ambient seismic noise. Front Earth Sci 6:251. https://doi.org/10.3389/feart.2018.00251

Delaney PT, Fiske RS, Miklius A, Okamura AT, Sako MK (1990) Deep magma body beneath the summit and rift zones of Kilauea Volcano, Hawaii. Science 247(4948):1311-1316. https://doi.org/10.1126/scien ce.247.4948.1311

Denlinger RP, Okubo P (1995) Structure of the mobile south flank of Kilauea Volcano, Hawaii. J Geophys Res Solid Earth 100(B12):24499-24507. https ://doi.org/10.1029/95jb01479

Dieterich JH (1988) Growth and persistence of Hawaiian volcanic rift zones. J Geophys Res Solid Earth 93:4258-4270. https://doi.org/10.1029/jb093 ib05p04258

Dieterich JH, Cayol V, Okubo P (2003) Stress changes before and during the Pu'u'Ō'ō-Kūpaianaha eruption. In: Helit C, Swanson DA, Takahashi TJ (eds) The Pu'u'Ō'ō-Kūpaianaha eruption of Kïlauea volcano, Hawai'i, the first 20 years U.S. Geological Survey Professional Paper 1676, pp 187-202

Donaldson C, Caudron C, Green RG, Thelen WA, White RS (2017) Relative seismic velocity variations correlate with deformation at Kilauea volcano. Sci Adv 3(6):e1700219. https://doi.org/10.1126/sciadv.1700219

Duputel Z, Ferrazzini V, Brenguier F, Shapiro N, Campillo M, Nercessian A (2009) Real time monitoring of relative velocity changes using ambient seismic noise at the Piton de la Fournaise volcano (La Réunion) from January 2006 to June 2007. J Volcanol Geotherm Res 184(1-2):164-173. https:// doi.org/10.1016/j.jvolgeores.2008.11.024

Gillard D, Rubin AM, Okubo P (1996) Highly concentrated seismicity caused by deformation of Kilauea's deep magma system. Nature 384(6607):343-346

Hadziioannou C, Larose E, Coutant O, Roux P, Campillo M (2009) Stability of monitoring weak changes in multiply scattering media with ambient noise correlation: laboratory experiments. J Acoust Soc Am 125(6):36883695. https://doi.org/10.1121/1.3125345

Heliker C, Swanson DA, Takahashi TJ (2003) The Pu'u O'o-Kupaianaha eruption of Kilauea Volcano, Hawai'i: the first 20 years. U.S. Geological Survey Professional Paper 1676, pp 29-51

Herrmann RB (1987) Surface wave inversion. Computer Programs in Seismology 4. Saint Louis Univ., Mo

Lin G, Shearer PM, Matoza RS, Okubo PG, Amelung F (2014) Three-dimensional seismic velocity structure of Mauna Loa and Kilauea volcanoes in Hawaii from local seismic tomography. J Geophys Res Solid Earth 119:43774392. https://doi.org/10.1002/2013jb010820

Lobkis OI, Weaver RL (2001) On the emergence of the Green function in the correlation of a diffuse field. J Acoust Soc Am 110:011-3017. https://doi. org/10.1121/1.1417528

Machacca-Puma R, Lesage P, Larose E, Lacroix P, Anccasi-Figueroa RM (2019) Detection of pre-eruptive seismic velocity variations at an andesitic volcano using ambient noise correlation on 3-component stations: Ubinas volcano, Peru, 2014. J Volcanol Geoth Res 381:83-100

Mordret A, Jolly AD, Duputel Z, Fournier N (2010) Monitoring of phreatic eruptions using Interferometry on Retrieved Cross-Correlation Function 
from Ambient Seismic Noise: Results from Mt. Ruapehu, New Zealand. J Volcanol Geoth Res 191:46-59

Neal CA, Brantley SR, Antolik L, Babb JL, Burgess M, Calles K, Cappos M, Chang JC, Conway S, Desmither L, Dotray P, Elias T, Fukunaga P, Fuke S, Johanson IA, Kamibayashi K, Kauahikaua J, Lee RL, Pekalib S, Miklius A, Million W, Moniz CJ, Nadeau PA, Okubo P, Parcheta C, Patrick MR, Shiro B, Swanson DA, Tollett W, Trusdell F, Younger EF, Zoeller MH, Montgomery-Brown EK, Anderson KR, Poland MP, Ball JL, Bard J, Coombs M, Dietterich HR, Kern C, Thelen WA, Cervelli PF, Orr T, Houghton BF, Gansecki C, Hazlett R, Lundgren P, Diefenbach AK, Lerner AH, Waite G, Kelly P, Clor L, Werner C, Mulliken K, Fisher G, Damby D (2019) The 2018 rift eruption and summit collapse of Kilauea Volcano. Science 363:367-374. https://doi. org/10.1126/science.aav7046

Obermann A, Planes T, Larose E, Campillo M (2013a) Imaging preeruptive and coeruptive structural and mechanical changes of a volcano with ambient seismic noise. J Geophys Res Solid Earth 118:6285-6294. https://doi. org/10.1002/2013jb0103

Obermann A, Planès T, Larose E, Sens-Schönfelder C, Campillo M (2013b) Depth sensitivity of seismic coda waves to velocity perturbations in an elastic heterogeneous medium. Geophys J Int 194(1):372-382. https:// doi.org/10.1093/gji/ggt04

Obermann A, Planès T, Hadziioannou C, Campillo M (2016) Lapse-timedependent coda-wave depth sensitivity to local velocity perturbations in 3-D heterogeneous elastic media. Geophys J Int 207(1):59-66. https://doi. org/10.1093/gji/ggw26

Olivier G, Brenguier F, Carey R, Okubo P, Donaldson C (2019) Decrease in seismic velocity observed prior to the 2018 eruption of Kilauea Volcano with ambient seismic noise interferometry. Geophys Res Lett 46(7):3734-3744. https://doi.org/10.1029/2018gl081609

Owen S, Segall P, Lisowski M, Miklius A, Denlinger R, Sako M (2000) Rapid deformation of Kilauea Volcano: global positioning system measurements between 1990 and 1996. J Geophys Res Solid Earth 105:1898318998. https://doi.org/10.1029/2000jb900109

Patrick M, Wilson D, Fee D, Orr T, Swanson D (2011) Shallow degassing events as a trigger for very-long-period seismicity at Kïlauea Volcano, Hawai 'i. Bull Volcanol 73:1179-1186. https://doi.org/10.1007/s00445-011-0475-y

Patrick M, Orr T, Sutton AJ, Lev E, Thelen W, Fee D (2016a) Shallowly driven fluctuations in lava lake outgassing (gas pistoning), Kilauea Volcano. Earth Planet Sci Lett 433:326-338. https://doi.org/10.1016/j.epsl.2015.10.052

Patrick M, Orr T, Swanson DA, Lev E (2016b) Shallow and deep controls on lava lake surface motion at Killauea Volcano. J Volcanol Geotherm Res 328:247-261. https://doi.org/10.1016/j.jvolgeores.2016.11.010

Patrick M, Dietterich HR, Lyons JJ, Diefenbach AK, Parcheta C, Anderson KR, Namiki A, Sumita I, Shiro B, Kauahikaua JP (2019) Cyclic lava effusion during the 2018 eruption of Kilauea Volcano. Science 366:6470
Pietruszka AJ, Heaton DE, Marske JP, Garcia MO (2015) Two magma bodies beneath the summit of Kilauea Volcano unveiled by isotopically distinct melt deliveries from the mantle. Earth Planet Sci Lett 413:90-100. https:// doi.org/10.1016/j.epsl.2014.12.0

Poland MP, Takahashi TJ, Landowski CM (2014) Characteristics of Hawaiian volcanoes. U.S. Geological Survey Professional Paper 1801, https://doi. org/10.3133/pp180

Poland MP, Peltier A, Bonforte A, Puglisi G (2017) The spectrum of persistent volcanic flank instability: a review and proposed framework based on Kilauea, piton de la Fournaise, and Etna. J Volcanol Geotherm Res 339:63-80. https://doi.org/10.1016/j.jvolgeores.2017.05.00

Rubin AM, Gillard D, Got JL (1998) A reinterpretation of seismicity associated with the January 1983 dike intrusion at Kilauea Volcano, Hawaii. J Geophys Res Solid Earth 103(B5):10003-10015. https://doi.org/10.1029/97jb0 3513

Seats KJ, Lawrence JF, Prieto GA (2012) Improved ambient noise correlation functions using Welch's method. Geophys J Int 188(2):513-523. https:// doi.org/10.1111/j.1365-246x.2011.05263.x

Sens-Schönfelder C, Wegler U (2006) Passive image interferometry and seasonal variations of seismic velocities at Merapi Volcano, Indonesia. Geophys Res Lett 45:67. https://doi.org/10.1029/2006gl027797

Snieder R, Grêt A, Douma H, Scales I (2002) Coda wave interferometry for estimating nonlinear behavior in seismic velocity. Science 295:2253-2255. https://doi.org/10.1126/science.1070015

Taira T, Brenguier F, Kong Q (2015) Ambient noise-based monitoring of seismic velocity changes associated with the $2014 \mathrm{Mw} 6.0$ South Napa earthquake. Geophys Res Lett 42:6997-7004. https://doi.org/10.1002/2015g 106530

Taira T, Nayak A, Brenguier F, Manga M (2018) Monitoring reservoir response to earthquakes and fluid extraction, Salton Sea geothermal field, California. Sci Adv 4(1):e1701536. https://doi.org/10.1126/sciadv.1701536

Weaver RL, Hadziioannou C, Larose E, Campillo M (2011) On the precision of noise correlation interferometry. Geophys J Int 185(3):1384-1392. https:// doi.org/10.1111/j.1365-246x.2011.05015.x

Wu S-M, Lin F-C, Farrell J, Shiro B, Karlstrom L, Okubo P, Koper K (2020) Spatiotemporal seismic structure variations associated with the 2018 Kilauea eruption based on temporary dense geophone arrays. Geophys Res Lett 47:e2019GL086668. https://doi.org/10.1029/2019GL086668

\section{Publisher's Note}

Springer Nature remains neutral with regard to jurisdictional claims in published maps and institutional affiliations.

\section{Submit your manuscript to a SpringerOpen ${ }^{\circ}$ journal and benefit from:}

- Convenient online submission

- Rigorous peer review

- Open access: articles freely available online

- High visibility within the field

- Retaining the copyright to your article

Submit your next manuscript at $\boldsymbol{\nabla}$ springeropen.com 